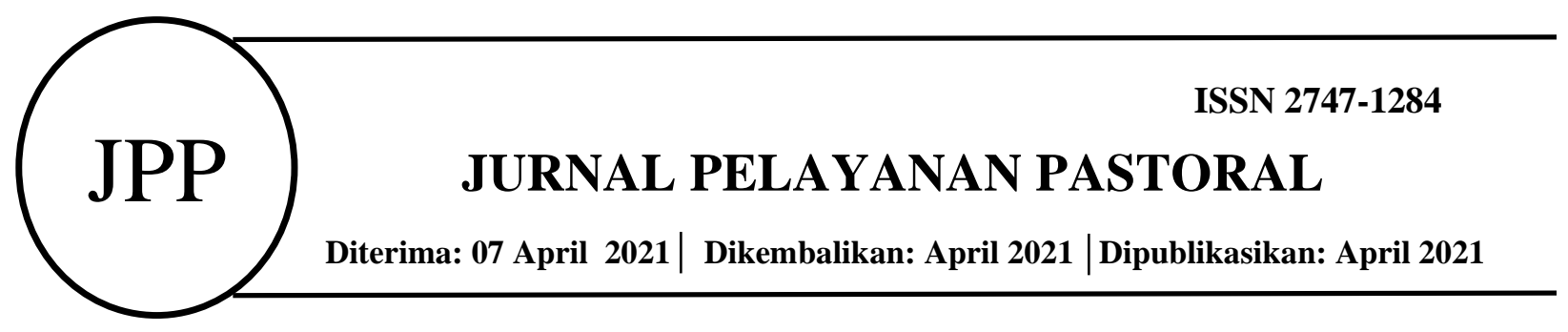

\title{
PARTISIPASI UMAT LINGKUNGAN \\ ST. MARIA MENGUNJUNGI ELISABET \\ TERHADAP NYANYIAN LITURGI EKARISTI DI PAROKI MDKS MALANG
}

\author{
Emmeria Tarihoran*1, Fiktus Suyanto*2 \\ ${ }^{1}$ Dosen Prodi Pendidikan dan Pengajaran Agama Katolik STP-IPI Malang \\ ${ }^{2}$ Guru SMA Kolese Gonzaga Jakarta Selatan \\ email: ${ }^{1}$ Emmriayohana@gmail.com, ${ }^{2}$ moderator@gonzaga.sch.id
}

\begin{abstract}
Abstrak
Partisipasi umat dalam nyanyian liturgi membutuhkan kesadaran dan keaktifan. Nyanyian liturgi merupakan bagian penting dalam membantu umat dalam merayakan liturgi, karena nyanyian memiliki kedudukan yang tidak terpisahkan dalam liturgi Ekaristi. Penelitian ini bertujuan untuk mendeskripsikan partisipasi umat Santa Maria mengunjungi Elisabeth dalam nyanyian Liturgi Ekaristi. Metode yang digunakan adalah pendekatan kuantitatif deskriptif. Jumlah sampel 72 terdiri dari 35 laki-laki dan 37 perempuan. Teknik pengumpulan data menggunakan kuesioner terbuka dan tertutup. Pengolahan data menggunakan F Persen dan Scoring. Hasil yang diperoleh menunjukkan bahwa partisipasi dalam nyanyian proprium kategori baik, dengan skor rata-rata 3,96. Partisipasi nyanyian pada kategori ordinarium sangat baik, dengan skor rata-rata 4,21. Partisipasi dalam mazmur tanggapan dan ayat pengantar Injil, menunjukkan kategori sangat baik dengan rata-rata skor 4,24. Pada bidang penilaian diri keikutsertaan nyanyian liturgi Ekaristi menunjukkan kategori baik dengan skor rata-rata 4,03. Kesadaran partisipasi umat bernyanyi dari awal hingga akhir lagu Ekaristi menunjukkan kategori baik, dengan skor 3,66. Faktor penghambat tidak tahu lagunya, lagunya susah, lagunya tidak Puji Syukur dengan persentase 56\%. Sedangkan faktor pendukung yaitu mengetahui lagunya mudah mengetahui lagunya dengan persentase 43,66\%. Kesimpulan keseluruhan mengenai keikutsertaan umat dalam nyanyian ekaristi liturgi di Bangsal St. Maria Mengunjungi Elisabeth berada pada kategori baik, dengan skor rata-rata 4,03.
\end{abstract}

Kata Kunci: Partisipasi, Liturgi Ekaristi, Nyanyian Liturgi

\begin{abstract}
The participation of the people in liturgical chant requires awareness and activeness. Liturgical chant is an important part of helping people celebrate the liturgy because singing has an inseparable position in the Eucharistic liturgy. This research proposes to describe the participation of the people of St. Maria Mengunjungi Elisabeth in the chanting of the Eucharistic Liturgy. The method employed is a descriptive quantitative approach. The whole sample of 72 consisted of 35 males and 37 females. The data collection technique applied open and closed questionnaires. Data processing using F Percent and Scoring. The results obtained indicate that the participation in the liturgical chant is in a good category, with an average score of 3.96. Chanting participation in the ordinarium category was very good, with an average score of 4.21. Participation in the respondent psalm and the introductory scripture to the gospel shows the category very good with an average score of 4.24. In the field of self-assessment, the participation of the Eucharistic liturgical chanting showed a good category with an average score of 4.03 . The awareness of the participation of the singing people from the beginning to the end of the Eucharistic song shows a good category, with a score of 3.66. The inhibiting factor is not knowing the song, the song is difficult, the song is not Praise Gratitude with a percentage of $56 \%$. While the supporting factor, namely knowing the song is easy to know the song with a percentage of $43.66 \%$. The overall conclusion regarding the participation of the people in the liturgical eucharistic chant in St. Maria Mengunjungi Elisabeth is in a good category, with an average score of 4.03.
\end{abstract}

Keywords: Participation, the Eucharistic Liturgy, Liturgical Chants 


\section{PENDAHULUAN}

Perayaan iman yang dirayakan dalam liturgi melibatkan baik perasaan maupun emosi; namun inti dari perayaan iman itu bukanlah pada emosi dan perasaan melainkan pada karya keselamatan yang dibawa oleh Kristus. Hal ini ditegaskan oleh Robertus Manik "Liturgi sebagai sebuah perayaan juga melibatkan perasaan dan emosi saat dirayakan, misalnya lagu yang indah, dekorasi yang bagus, asap wiruk yang wangi, dan lain-lain; namun bukan emosi dan perasaan itu yang menjadi inti perayaan iman itu." (Manik, 2020)

Musik adalah satu aspek penting dalam Liturgi Gereja. "Musik selalu menjadi bagian ungkapan dan media komunikasi manusia" (Martasudjita, 2011:190). Tradisi musik Gereja merupakan kekayaan yang tak terperikan nilainya, lebih gemilang dari ungkapan-ungkapan seni lainnya, terutama karena nyanyian suci yang terikat pada kata-kata merupakan bagian Liturgi meriah yang penting atau integral (SC. 112). Nyanyian dalam Liturgi Gereja tidak bisa lepas dengan istilah musik liturgi. Nyanyian liturgi adalah bagian dari musik liturgi karena yang tergolong dalam Musik liturgi ialah: nyanyian dan alat musik. Gereja Katolik juga memakai istilah musik dalam arti dan bentuk yang khas. Musik gereja secara umum berbentuk musik religi/musik rohani yang pada umumnya juga dimiliki oleh agama mana pun. Musik religi/musik rohani ialah musik yang mengungkapkan atau mengandung tema-tema rohani. Oleh karena musik rohani/religi yang bersifat umum itu oleh gereja tidak dimaksudkan untuk digunakan dalam perayaan liturgi (Krismiyanto, 2018:1-2).

Pada dasarnya syair-syair nyanyian Mazmur-mazmur sudah ada sejak perjanjian lama, Gereja melanjutkan tradisi itu dan mengembangkannya: "berkata-katalah seorang kepada yang lain dalam Mazmur, kidung puji-pujian dan nyanyian rohani. Bernyanyi dan bersorak-sorailah bagi Tuhan dengan segenap hati (Ef 5:19)"(Prier, 2015:5).

Nyanyian dalam liturgi Ekaristi meliputi, nyanyian Perarakan Masuk, Ordinarium (Tuhan Kasihanilah Kami, Kemuliaan, Pater Noster, dan Anak Domba Allah), nyanyian antar bacaan, Alleluya sebelum Injil, Aklamasi Kudus, Persiapan Persembahan, Komuni, dan Penutup (Krismiyanto, Dimas 2018:39). Nyanyian mempunyai kedudukan yang integral dalam liturgi Ekaristi. Oleh sebab itu umat juga diharapkan partisipasi aktif dalam nyanyian-nyanyian liturgi Ekaristi tersebut (Kosasi., 2010:35).

Pada dasarnya banyak umat yang telah berpartisipasi aktif dalam nyanyian, namun juga tidak sedikit yang pasif, bahkan umat berkolaborasi aktif dan pasif dalam berpartisipasi terhadap nyanyian liturgi Ekaristi. Masih banyak umat kurang mempunyai tanggung jawab untuk menyanyi. Mereka mengandalkan koor yang dianggap sebagai tugasnya dalam perayaan liturgi Ekaristi." Hal ini dapat dilihat dari persiapan dan kesiapan umat untuk mau membawa Puji Syukur sebagai buku nyanyian umat. Banyak umat yang menganggap tidak penting untuk membawa buku Puji Syukur, sehingga paroki bertindak menyiapkan Puji Syukur di setiap bangku agar umat terlibat dalam nyanyian. Partisipasi Umat cenderung pada selera instrumen musik saja, sedangkan isi, makna, tujuan, serta nilai liturgis dari syair nyanyian tersebut kadang diabaikan. Suatu contoh kasus, kerap kali dijumpai umat menyanjung petugas kor ketika memilih dan menyanyikan nyanyian yang bernada serta memiliki instrumen indah.

Permasalahan umum di atas juga di alami umat lingkungan Maria Mengunjungi Elisabeth. Sejauh ini petugas kor begitu minimalis dan tidak sebanding dengan jumlah umat yang berdomisili di lingkungan. Ada kemungkinan umat kurang partisipasi atau enggan untuk menyanyi. Beberapa tokoh lingkungan mengungkapkan bahwa sejumlah umat yang kurang memiliki kesadaran untuk berpartisipasi terhadap nyanyian liturgi atas dasar tidak hobi atau tidak memiliki kecakapan dalam menyanyi. Minimnya partisipasi umat lingkungan Maria Mengunjungi 
Elisabeth juga akibat dari rasa bosan terhadap nyanyian yang tidak menarik atau monoton. maksudnya ialah, umat berpartisipasi dalam nyanyian ketika nyanyian itu indah didengar, harmonis, dan paham cara menyanyikan lagu tersebut.

\section{METODE PENELITIAN}

Metode menggunakan pendekatan kuantitatif deskriptif. Variabel yang diukur adalah variabel tunggal, yakni: Partisipasi Umat terhadap Nyanyian Liturgi Ekaristi dengan sub-sub variabel: a. Partisipasi terhadap nyanyian Proprium dan Ordinarium b. Partisipasi terhadap nyanyian Mazmur dan Bait Pengantar Injil. c. Faktor penghambat dan pendukung. Jumlah sampel sebanyak 72 terdiri dari laki-laki 35 orang dan perempuan 37 orang. Teknik pengumpulan data menggunakan angket terbuka dan tertutup. Pengolahan data dengan menggunakan F Persen dan Scoring.

\section{HASIL DAN PEMBAHASAN}

\section{Partisipasi Umat Terhadap Nyanyian Liturgi Berdasarkan Ajaran Kitab Suci}

Pada dasarnya sejak zaman Gereja perdana sudah mengenal nyanyian dan musik instrumental. Berdasarkan Kitab Suci Perjanjian Baru, kata "nyanyian" atau "bernyanyi" ditemukan sebanyak 36 kali (Krismiyanto, 2018:18). Injil Mark 14: 26 dan Mat 26:30, menuliskan bahwa Yesus dan Para Rasul menyanyikan kidung "Hallel” setelah merayakan Perjamuan Paskah. Praktik nyanyian Gereja Perdana dapat pula dilihat dalam Surat Efesus 5:19 dan Kolose 3:16-17, yang menyarankan umat menyanyikan kidung puji-pujian dan nyanyian rohani dalam pertemuan jemaat.

Pada abad kedua gereja perdana juga mengenal sejumlah madah yang sampai sekarang masih dinyanyikan misalnya "Gloria In Excelsis Deo", nyanyian ini diatributkan kepada Paus St. Telesphorus, dan pada abad ke-empat muncul nyanyian "Te Deum” yang diatributkan kepada St. Ambrosius dan St. Agustinus (Krismiyanto, 2018:19).

Rasul Paulus menganjurkan kepada himpunan umat yang menantikan kedatangan Tuhan, supaya mereka melakukan Mazmur, madah, dan lagu-lagu rohani (lih. Kol 3:16). "Gereja Perdana mengenal dengan baik nyanyian sebagai unsur kehidupan liturgi” (Martasudjita, 2011:191). Melalui nyanyian, doa-doa liturgis yang diungkapkan secara lebih menarik oleh petugas dapat membantu umat-umat yang hadir membuka telinga batin, serta dapat membangkitkan suasana hati mereka untuk mengalami hal-hal surgawi yang sangat indah dalam suatu perayaan liturgi yang dirayakan dengan sadar dan aktif, agung, sakral, hikmat, dan penuh makna (Krismiyanto dan Dimas, 2018:18).

\section{Partisipasi Umat Terhadap Nyanyian Liturgi Berdasarkan Ajaran Gereja}

Partisipasi umat terhadap nyanyian liturgi Ekaristi di tegaskan oleh berbagai dokumen

Gereja. Konsili Vatikan II dalam konstitusi tentang Liturgi Suci: Sacrosantum Concilium. Musicam Sacram, dan Pedoman Umum Misale Romawi. Dokumen Konsili Vatikan II Konstitusi tentang Liturgi Suci, Sacrosanctum Concilium, menjelaskan bahwa musik/nyanyian Liturgi, merupakan doa-doa yang dinyanyikan. Doa-doa liturgis yang dinyanyikan, digubah untuk perayaan suci. Nyanyian yang memiliki bobot kudus, yang merupakan bagian penting dan integral dalam perayaan Liturgi.

Liturgi yang laksanakan dengan baik menghasilkan serangkaian efek yang baik bagi mereka yang berpartisipasi (Macdonald, 2013). Salah satu aspek yang berubah dalam Liturgi 
Gereja setelah Konsili Vatikan II adalah terbukanya kesempatan bagi umat untuk berpartisipasi secara aktif dalam perayaan liturgi Gereja. Musik adalah sebuah tambahan penting untuk upacara baru liturgi dan prioritas liturgi dan musisi harus memungkinkan orang-orang menyanyikan doa mereka (Quinn, 1983). Dalam Konstitusi Liturgi dijelaskan bahwa hakikat liturgi menuntut partisipasi secara penuh, sadar, dan aktif dari umat beriman yang terlibat di dalamnya (SC 14). Dalam Konstitusi Liturgi dijelaskan bahwa hakikat liturgi menuntut partisipasi secara penuh, sadar, dan aktif dari umat beriman yang terlibat di dalamnya ( $S C$ 14). Partisipasi yang penuh secara esensial menunjuk pada partisipasi yang diungkapkan melalui suara, gerak badan juga seluruh hati dan pikiran (bdk. $S C$ 11). Dengan demikian, partisipasi secara penuh menunjukkan keterlibatan aktif umat baik secara batin, pikiran, hati, maupun suara dan gerak badan. Konstitusi Liturgi partisipasi aktif umat secara sadar dalam mencapai pemahaman yang benar akan misteri iman yang dirayakan (SC.48). Partisipasi secara sadar dan aktif juga menyangkut persiapan diri kita ketika memilih nyanyian liturgi. Para petugas liturgi khususnya kor, secara sadar tahu dan paham bahwa pemilihan nyanyian liturgi harus sesuai dengan tema perayaan dan bagian-bagiannya. Ia sadar bahwa penggunaan nyanyian dalam perayaan liturgi khususnya Ekaristi tidak boleh asalasalan.(Hermawan, 2017).

Menentukan dan menggunakan nyanyian liturgi dengan tepat akan membantu penghayatan umat terhadap perayaan yang sedang berlangsung. Dengan pemilihan nyanyian yang tepat, umat beriman dapat menyesuaikan hati dengan apa yang mereka ucapkan/nyanyikan (bdk.SC 11). Selanjutnya Konstitusi liturgi menegaskan bahwa upacara liturgi menjadi lebih agung, bila ibadat kepada Allah dirayakan dengan nyanyian meriah, bila dilayani oleh petugas-petugas liturgi, dan bila umat beriman ikut serta secara aktif (SC. 113)

Dalam pedoman liturgi secara tidak langsung dinyatakan bahwa Ekaristi dirayakan sesuai dengan keadaan umat setempat (lih. PUMR 18). Perhatian terhadap keadaan umat sangat penting demi mewujudkan partisipasi umat beriman dalam perayaan Ekaristi menurut tugas dan peran masing-masing sehingga umat dapat. memetik buah hasil Ekaristi sepenuh-penuhnya (bdk. PUMR 17 dan 20). Oleh Karena itu, hendaknya seluruh perayaan dirancang sedemikian rupa sehingga umat yang hadir dapat berpartisipasi secara sadar, aktif, dan penuh dengan jiwa dan raganya, yang dikobarkan dengan iman, harapan, dan kasih (PUMR 18). (Institutio Generalis Misale Romani. Terjemahan KWI, 2013).

PUMR artikel 41 mengungkapkan pentingnya peranan nyanyian dalam perayaan liturgi, sehingga Peran umat dalam berpartisipasi terhadap nyanyian liturgi di junjung tinggi. Berikut ini beberapa hal pokok yang perlu di perhatikan dalam kriteria pemilihan nyanyian (Martasudjita, 2007:45): a. Nyanyian liturgi yang dipilih harus melayani seluruh umat beriman; b. Nyanyian liturgi harus bias melibatkan partisipasi umat; c. Nyanyian liturgi harus mengungkapkan iman akan misteri Kristus; d. Nyanyian liturgi harus sesuai dengan masa dan tema liturgi; e. Nyanyian liturgi harus sesuai dengan hakikat masing-masing bagian; f. Pemilihan nyanyian liturgi perlu memperhatikan pertimbangan pastoral dan praktis.

\section{Bentuk Partisipasi Umat Terhadap Nyanyian Liturgi Ekaristi}

\section{Nyanyian Proprium}

\section{a. Nyanyian Pembuka}

Nyanyian pembuka merupakan bagian dari ritus pembuka. Nyanyian pembuka hendaknya diperhitungkan proporsi waktu untuk menyanyikan sehingga makna yang terkandung dalam ritus pembuka tidak mengalahkan keunggulan liturgi Sabda dan liturgi Ekaristi. (Suryanugraha, 
2015:62) Nyanyian pembuka dinyanyikan ketika umat dalam keadaan berkumpul, sementara imam dan para pelayan berarak menuju ke atar. Beberapa hal yang kerap sekali keliru dalam pelaksanaan nyanyian pembuka yaitu: nyanyian yang terlalu panjang sehingga imam menunggu terlalu lama di altar, sebaliknya nyanyian yang terlalu singkat sementara imam baru akan mulai mendupai altar.

Nyanyian Pembuka dinyanyikan oleh seluruh umat sambil berdiri. Nyanyian pembuka bertujuan untuk menyambut perarakan imam dan para petugas liturgi menuju altar. Partisipasi aktif umat dengan sikap hormat dan siaga menyambut kedatangan Tuhan. Nyanyian pembuka mempunyai beberapa peran Membuka Perayaan Ekaristi. Membuka kesatuan umat yang berhimpun. Mengantar masuk ke dalam misteri iman yang dirayakan pada liturgi tersebut, (sesuai masa dan pesta liturgi). Mengiringi berjalannya imam beserta pembantu-pembantunya menuju altar (Krismiyanto, 2011:14).

\section{b. Nyanyian Persiapan Persembahan}

Fungsi nyanyian persiapan persembahan adalah mengiringi perarakan persembahan dan sekaligus untuk membina kesatuan hati umat dan mengantar umat masuk ke dalam misteri Ekaristi suci yang kini sedang dipersiapkan dengan persembahan itu. Nyanyian persembahan di tempatkan dalam rangka persembahan suci dan anggur dan uang dari umat sebagai usaha jerih payah manusia. Nyanyian persembahan ini berlangsung sampai persembahan diletakkan di altar. Apabila tidak ada nyanyian persembahan, organis dapat memainkan instrumen secara lembut untuk menciptakan suasana liturgi yang sesuai.

\section{c. Nyanyian Komuni}

Nyanyian Komuni dimaksud-kan untuk mengiringi umat dalam menyambut Tubuh Kristus. Nyanyian Komuni sekaligus juga meneguhkan persatuan dan persaudaraan umat secara lahir batin sebagai tubuh Kristus, sebab dari tubuh Kristus yang mereka santap mengalir buah kesatuan umat. Nyanyian komuni juga menciptakan suasana doa bagi umat yang sedang berjumpa dengan Tuhan secara sakramental dalam komuni (Krismiyanto, 2011)

Nyanyian Komuni mulai dinyanyikan pada saat imam menyambut Tubuh dan Darah Kristus. Nyanyian komuni bertujuan agar (1) umat yang secara batin bersatu dalam komuni juga menyatakan persatuan secara lahir dalam nyanyian bersama, (2) menunjukkan kegembiraan hati, dan (3) menggarisbawahi corak jemaat dari perarakan komuni. Nyanyian komuni berlangsung selama umat menyambut Tubuh Kristus. Jika sesudah komuni masih ada nyanyian, maka nyanyian komuni harus diakhiri pada waktunya (PUMR 86). (Institutio Generalis Misale Romani. Terjemahan KWI, 2013).

\section{d. Nyanyian Penutup}

Nyanyian penutup dapat bertema syukur, mengungkapkan misteri yang baru saja dirayakan, atau memberi pesan untuk perutusan (Suryanugraha, 2015:106). Nyanyian penutup pada umumnya dinyanyikan langsung sesudah salam pengutusan dari imam. Fungsi nyanyian penutup dalam Liturgi Ekaristi adalah: Menutup perayaan ekaristi, memberi gairah dan semangat kepada umat agar mereka pergi menjalankan perutusan untuk mewartakan damai dan kebaikan Tuhan dengan gembira. Mengiringi perarakan imam dan para petugas liturgi memasuki sakristi (Kosasi, 2010). 


\section{Nyanyian Ordinarium}

Nanyian Ordinarium merupakan istilah yang digunakan untuk memudahkan penyebutan lima nyanyian yang tidak pernah berubah dalam Perayaan Ekaristi. Nyanyian Ordinarium ini meliputi, Tuhan Kasihanilah Kami (Kyrie), Kemuliaan (Gloria), Syahadat (Credo), Kudus (Sanctus) dan Anak Domba Allah. Masing-masing nyanyian memiliki tingkatan yang tidak sejajar. Nyanyian Kudus mempunyai tingkatan terpenting, sebab berada dalam bagian Doa Syukur Agung yang merupakan bagian inti Liturgi Ekaristi(Alf., 2017). Penelitian ini menggunakan kategori yang menurut Suryanugraha (2015) Pater Noster (Bapa Kami) termasuk bagian dari Ordinarium.

\section{a. Nyanyian Tuhan Kasihanilah Kami/ Kyrie}

PUMR No. 52 memberi arahan dan fungsi nyanyian Tuhan Kasihanilah Kami. Adapun fungsi itu ialah (1) bersifat seruan kepada Tuhan dan memohon belas kasihan. (2) menyapa Tuhan sebagai penyelamat di tengah umat. Dengan demikian, sifat nyanyian Tuhan Kasihanilah Kami ialah memberi hormat kepada Kristus sebagai Kyrios atau Tuhan, dan bersifat memohon (Prier, 2015:25). Selanjutnya dalam PUMR No. 52 ditegaskan tentang model menyanyikan Tuhan Kasihanilah Kami yaitu:

1) Seruan "Tuhan kasihanilah kami” dibawakan oleh imam/solis dan diulang satu kali oleh umat.

2) Seruan "Kristus kasihanilah kami" dibawakan oleh imam/solis dan diulang satu kali oleh umat,

3) Seruan "Tuhan kasihanilah kami" dibawakan oleh imam/solis dan diulang satu kali oleh umat.

\section{b. Nyanyian Gloria}

Kemuliaan adalah madah yang paling di hormati dari zaman Kristen kuno. Lewat madah ini gereja yang berkumpul atas dorongan Roh Kudus memuji Allah, dan Anak Domba Allah, serta memohon belas kasih-Nya. Teks madah ini tidak boleh diganti dengan teks lain. Kemuliaan dibuka oleh imam atau, lebih cocok, oleh solis atau kor, kemudian dilanjutkan oleh seluruh umat bersamasama atau oleh kor, kemudian dilanjutkan oleh seluruh umat bersama-sama, atau oleh umat dan paduan suara bersahut-sahutan, atau hanya oleh koor. Kalau tidak dilagukan, madah kemuliaan dilafalkan oleh seluruh umat bersama-sama atau oleh dua kelompok umat secara bersahutsahutan.

Kemuliaan dilagukan atau diucapkan pada hari-hari raya dan pesta, pada perayaanperayaan meriah, dan pada hari Minggu di luar Masa Adven dan Pra-paskah (PUMR 53). Prier (2015:25) mencatat fungsi Nyanyian Kemuliaan 1) Menyatakan Syukur kepada Kristus; 2) Merayakan Hari Minggu atau Hari Raya; 3) Sebagai bentuk ungkapan syukur atas kehadiran Tuhan di tengah umat-Nya; 4) Sebagai bentuk pujian kepada Allah di surga; 5) Merupakan suatu warisan Gereja yaitu madah Kuno yang berbentuk himne untuk awal misa.

\section{c. Nyanyian Credo}

Nyanyian Credo atau Aku Percaya adalah bagian nyanyian bersifat fakultatif. Fakultatif maksudnya boleh dinyanyikan atau hanya di daras saja. Melagukan syahadat memang tidak dilarang, namun juga tidak diwajibkan. Yang terpenting adalah umat harus bisa ikut menyanyikan jika syahadat dinyanyikan. Bila durasi diperkirakan akan terlalu lama, sebaiknya syahadat tidak harus dipaksakan untuk dinyanyikan (Suryanugraha, 2015:84). 
Fungsi dari nyanyian Credo ialah: Seluruh umat yang berhimpun dapat menanggapi sabda Allah yang dimaklumkan dari Alkitab dan dijelaskan dalam homili dan mencari pegangan untuk itu dengan membaharui iman. Nyanyian Credo ini bersifat Pernyataan. Nyanyian Credo dapat dibawakan dalam bentuk ucapan bersama, bersahut-sahutan, dinyanyikan dengan lagu Khusus, dan dilagukan dengan nyanyian lain yang sesuai (contoh MB 226) untuk Misa anak (Prier, 2015:27)

\section{d. Nyanyian Aklamasi Kudus}

Nyanyian Kudus (Sanctus) adalah nyanyian partisipasi umat dalam Doa Syukur Agung. Syair sebaiknya seperti yang ada dalam Ordo Missae. Karena karakternya aklamasi, maka syair itu dapat diulang-ulang atau diberi tambahan sejauh masih sesuai dengan teks aslinya dari Ordo Missae. Maka dari itu syair Kudus yang kurang mengindahkan teks resmi atau terlalu jauh dari teks asli itu, sebaiknya tidak digunakan. Suatu contoh pada Madah Bakti No. 252, Misa E. Harjowardoyo (cetakan ke-134, 2011) (Suryanugraha, 2015:94)

Melihat peranan Nanyian Kudus dalam liturgi Ekaristi, berikut ini dirangkum fungsi, sifat, dan bentuk dari nyanyian tersebut Fungsi dari Nyanyian Kudus adalah mengikutsertakan/jawaban umat dalam Doa Syukur Agung. Sifat dari Nyanyian: Harus menggerakkan umat, meriah, dan singkat dan bentuknya dengan teks tradisional (resmi)(Prier, 2015:28).

\section{e. Nyanyian Pater Noster (Bapa Kami)}

Dalam doa Tuhan, Bapa kami, umat beriman memohon rezeki sehari-hari. Bagi umat Kristen rezeki sehari-hari ini terutama adalah Roti Ekaristi. Umat juga memohon pengampunan dosa, supa anugerah kudus itu diberikan kepada umat yang kudus. Imam mengajak jemaat untuk berdoa, dan seluruh umat beriman membawa bapa kami bersama-sama dengan imam. Kemudian imam sendirian mengucapkan embolisme yang diakhiri oleh jemaat dengan doksologi. Embolisme itu menguraikan isi permohonan terakhir dalam bapa kami dan memohon agar seluruh umat dibebaskan dari kejahatan. Baik ajakan imam dan bapa kami, maupun embolisme dan doksologi tersebut dilagukan atau di daras dengan suara yang jelas. (PUMR 81).

Nyanyian Bapa Kami adalah sifat doa yang bentuknya diucapkan atau dinyanyikan dengan memakai kata-kata "yang diajarkan Kristus sendiri". Berikut ini fungsi dari nyanyian bapa kami: 1) Persiapan menyambut komuni; 2) Menciptakan persatuan sebagai anak-anak seBapa. Kalau doa ini dinyanyikan dalam Bahasa latin, hendaknya dipakai lagu yang sudah disahkan; tetapi jika dinyanyikan dalam Bahasa pribumi, gubahan tersebut haruslah disahkan oleh pemimpin gerejawi yang berwenang di daerah setempat. Pada prinsipnya, nyanyian bapa kami yang boleh digunakan dalam liturgi ialah isi syair sesuai dengan doa bapa kami yang ditawarkan Injil kita (Kosasi., 2010:25) sepatutnya dipilih melodi yang meditative, yang mengantar umat untuk berdoa, bukan malah bergoyang (Suryanugraha, 2015: 97).

\section{f. Nyanyian Anak Domba Allah}

Nyanyian Anak Domba Allah berfungsi untuk mengiringi pemecahan roti, mengiringi penyampaian Vsalam damai, dan persiapan terakhir untuk menyambut komuni. Adapun sifat nyanyian ini ialah permohonan yang agak tenang (Prier, 2015:28).

Sementara imam memecah-mecahkan roti dan memasukkan sepotong kecil roti itu ke dalam piala berisi anggur dilagukan Anak Domba Allah, seturut ketentuan, oleh paduan suara atau solis dengan jawaban oleh umat. Kalau tidak dilagukan, Anak Domba Allah di daras dengan suara lantang. Karena fungsinya mengiringi pemecahan roti. Nyanyian ini boleh diulang-ulang 
seperlunya sampai pemecahan roti selesai. Pengulangan terakhir ditutup dengan seruan: berilah kami damai (PUMR 83).

\section{g. Peran Nyanyian Mazmur Tanggapan}

Pemazmur menyanyikan ayat-ayat mazmur dari mimbar atau tempat lain yang cocok. Seluruh jemaat tetap duduk dan mendengarkan, dan sesuai ketentuan, umat ambil bagian dengan melagukan ulangan. Kecuali kalau seluruh mazmur dilakukan sebagai satu nyanyian utuh tanpa ulangan. Akan tetapi untuk mempermudah kan umat berpartisipasi dalam mazmur tanggapan, disediakan juga sejumlah mazmur dengan ulangan yang dapat dipakai pada masa liturgi atau pesta orang kudus. Bila dilagukan, mazmur tersebut dapat dipergunakan sebagai pengganti teks yang tersedia, dalam Buku Bacaan Misa (Lektionarium). Kalau tidak dilagukan, hendaknya mazmur tanggapan didaras sedemikian rupa sehingga membantu permenungan sabda Allah. (PUMR 61c).

Mazmur tanggapan merupakan bagian pokok dalam liturgi Sabda. Materi mazmur tanggapan diambil dari Kitab Suci dan disesuaikan dengan bacaan pertama, dimaksudkan untuk memperdalam renungan atas sabda Allah yang baru saja kita dengarkan dalam bacaan yang mendahuluinya. Mazmur tanggapan sebaiknya dinyanyikan, tetapi dapat juga dibacakan atau didaraskan, sedangkan umat berpartisipasi dalam menyanyikan ulangan. Dalam keadaan tertentu, ayat-ayat mazmur tidak perlu dinyanyikan semuanya. Cukup diambil dua atau tiga bait saja kasus konkret: bila bacaan-bacaan hari itu: kebetulan semua panjang (Prier, 2015:29).

\section{h. Peranan Bait Pengantar Injil}

Sesudah bacaan yang langsung mendahului Injil, dilagukan bait pengantar Injil, dengan atau tanpa Alleluia, seturut ketentuan rubrik dan sesuai dengan masa liturgi yang sedang berlangsung, aklamasi ini merupakan ritus atau kegiatan tersendiri. Dengan aklamasi ini merupakan ritus atau kegiatan tersendiri. Dengan aklamasi ini jemaat beriman menyambut dan menyapa Tuhan yang siap bersabda kepada mereka dalam Injil, sekaligus menyatakan iman. Seluruh jemaat berdiri dan melagukan bait pengantar Injil, dipandu oleh paduan suara atau solis (PUMR 62).

Bait pengantar Injil mempersiapkan umat untuk mendengarkan Injil yang akan diwartakan. Pada saat pengantar Injil dinyanyikan, semua umat yang hadir berdiri sebagai ungkapan kesiapan dan penghormatan akan Kristus yang akan bersabda melalui Injil. Nyanyian ini umat berpartisipasi dengan berdiri dan melagukan secara bersama-sama. Nyanyian Alleluia sebagai Bait Pengantar Injil dinyanyikan sepanjang tahun kecuali pada masa papraskah. Alleluia seharusnya dinyanyikan dan tidak dibacakan. Apabila bait pengantar Injil tidak dinyanyikan, maka ditiadakan saja(Prier, 201529).

\section{Faktor Penghambat dan Pendukung Partisipasi Umat Terhadap Nyanyian Liturgi}

Petugas koor atau paduan suara menjadi faktor penghambat apabila: a) Menggantikan suara umat; b) Koor sebagai ajang pertunjukan; c) Jika nyanyian belum dikenal umat. Menjadi faktor pendukung jika koor membantu dan mendorong umat untuk menyanyi. Nyanyian koor mampu menyentuh hati umat.

Paduan suara membantu umat dalam berliturgi secara khidmat dan baik. Para petugas kor bukan hanya sekedar bernyanyi, melainkan mereka mengambil tugas luhur yaitu mewartakan Sabda dan misteri Allah. Melalui nyanyian-nyanyian itu, umat terbantu masuk ke dalam misteri 
penyelamatan yang sedang dirayakan dalam perayaan Ekaristi (Krismiyanto dan Dimas, 2018:54).

Dirigen dan Pengiring Dirigen adalah seorang pemimpin nyanyian yang bertanggungjawab atas kor atau paduan suara. Dirigen dan pengarang dapat menjadi faktor pendukung dan faktor penghambat. Dirigen dan Pengiring menjadi faktor penghambat apabila: a) Tidak menguasai musik dan kurangnya latihan; b) Penampilan dirigen berlebihan; c) Tidak membangun komunikasi yang baik dengan umat dan pemimpin liturgi; c) Tidak memperhatikan keseimbangan antara nyanyian dan iringan.

Dirigen dan Pengiring menjadi faktor pendukung apabila: a) Menguasai musik; b) Mengenal dengan baik anggota koor; c) Membangun komunikasi yang baik dengan umat dan pemimpin liturgi. Dirigen dan pengiring menjadi faktor penghambat apabila: a) Menguasai musik; b) Mengenal dengan baik anggota koor; c) Membangun komunikasi yang baik dengan umat dan pemimpin liturgi.

Dirigen adalah seorang pemimpin nyanyian yang bertanggungjawab atas kor atau paduan suara. Dirigen dan pengarang dapat menjadi faktor pendukung dan faktor penghambat apabila: a) Tidak menguasai musik dan kurangnya latihan; b) Penampilan dirigen berlebihan; c) Tidak membangun komunikasi yang baik dengan umat dan pemimpin liturgi; d) Tidak memperhatikan keseimbangan antara nyanyian dan iringan.

\section{KESIMPULAN}

Partisipasi aktif umat dalam nyanyian liturgi Ekaristi sangat dibutuhkan, sebab umat merupakan bagian Tubuh Mistik Kristus dan masing-masing mengambil peran sebagaimana mestinya, sehingga Ekaristi menjadi perayaan seluruh umat yang hadir secara utuh. Peran serta petugas nyanyian bukan meniadakan partisipasi umat melainkan membantu partisipasi umat. Nyanyian yang dinyanyikan dengan baik oleh petugas terarah pada tujuan membangkitkan suasana hati, untuk mengalami hal-hal surgawi yang sangat indah. Oleh sebab itu, menuntut partisipasi aktif umat dalam suatu perayaan liturgi yang dirayakan dengan sadar dan aktif, agung, sakral, hikmat, dan penuh makna.

Partisipasi aktif umat meliputi keterlibatan umat dalam menyanyi mendengarkan dengan penghayatan yang benar. Partisipasi dalam bentuk fisik atau keikutsertaan umat dalam menyanyi dan hening atau mendengarkan nyanyian-nyanyian oleh paduan suara, merupakan keikutsertaan yang sepenuhnya, sadar, dan aktif, apabila ia menyadari akan keterlibatannya, serta memohon bantuan dan bekerja sama dengan Roh Kudus.

Hasil Penelitian ini menunjukkan bahwa secara keseluruhan partisipasi umat dalam nyanyian liturgi Ekaristi di Lingkungan St. Maria Mengunjungi Elisabeth, menunjukkan bahwa jumlah responden terbanyak menjawab $\mathrm{B}$ dengan persentase 44,4\%. dengan rata-rata skor 4,03 termasuk kategori Baik. Partisipasi Umat terhadap Nyanyian Proprium yang meliputi nyanyian pembuka, nyanyian persembahan, nyanyian komuni, dan nyanyian penutup $83 \%$. dengan ratarata skor 3.96 termasuk kategori baik. Partisipasi Umat terhadap Nyanyian Ordinarium. nyanyian Tuhan kasihanilah kami, nyanyian kemuliaan, nyanyian aku percaya, nyanyian Bapa kami, nyanyian kudus, 82 dan nyanyian Anak Domba Allah. 43.47\% dengan rata-rata skor 4.21 termasuk kategori Sangat Baik.

Partisipasi Umat dalam Nyanyian Mazmur Tanggapan dan Bait Pengantar Injil 45.83\%. dengan rata-rata skor 4.24 termasuk kategori Baik. Kesadaran Partisipasi Umat Untuk Menyanyi Dari Awal Hingga Akhir Nyanyian Ekaristi 43.8\%. dengan rata-rata skor 3.66 masuk dalam kategori baik. 


\section{DAFTAR PUSTAKA}

Alf., K. (2017). Merayakan Ekaristi Yang Berbuah Dan Mengenal tata Perayaan Perkawinan. Malang: DIOMA.

Departemen Dokumentasi dan Penerangan KWI Terjemahan: R. Hardawiryana, S. . (1993). Dokumen Konsili Vatikan II Konstituti 'Sacrocanctum Concilium'(SC) Tentang Liturgi Suci. Jakarta: OBOR.

Hermawan, A. J. (2017). Pengaruh Nyanyian Liturgi "Bbt"Terhadap Partisipasi Kaum Muda Dalam Perayaan Ekaristi. TEOLOGI, 6(2), 187-200. Retrieved from https://ejournal.usd.ac.id/index.php/jt/article/viewFile/1000/778

Institutio Generalis Misale Romani. Terjemahan KWI, K. L. (2013). Pedoman Umum Misale Romawi (PUMR)(Cetakan II). Flores, NTT: NUSA INDAH. Retrieved from https://cupdf.com/document/pumr-pedomanumummisaleromawi.html

Kosasi., A. A. (2010). Kembali Ke Jiwa Musik Liturgis. Jakarta: OBOR.

Krismiyanto, A. (2011). Meningkatkan Peran Serta Petugas Liturgi. Malang: Komlit Keuskupan Malang.

Krismiyanto Alf.Pr, D. D. (2018). Nyanyian dan Musik Liturgi dalam Perayaan Ekaristi. Malang: Komisi Liturgi Keuskupan Malang.

Macdonald, M. (2013). Mass Performance: How Material Liturgies Enact the Spiritual. Liturgy, 28(1), 31-42. Retrieved from https://doi.org/10.1080/0458063X.2012.724313

Manik, R. P. (2020). Formalitas Liturgi dan Realitas Hidup Umat dalam Teologi Liturgi. In Y. Robert Pius Manik, Gregorius Pasi (Ed.), Berteologi Baru Untuk Indonesia (pp. 322-330). Yogyakarta: Kanisius.

Martasudjita, E. \& Kristanto, J. (2007). Panduan Memilih Nyanyian Liturgi. Yogyakarta: Komisi Liturgi Keuskupan Semarang.

Martasudjita, E. (2011). Liturgi: Pengantar untuk Studi dan Praksis Liturgi. Yogyakarta: Kanisius.

Prier, K. E. (2015). Panduan Musik Liturgi. Yogyakarta: Pusat Musik Liturgi.

Quinn, F. C. (1983). The New State of Music in the Liturgy. Liturgy, 3(3), 45-52. Retrieved from https://doi.org/10.1080/04580638309409856

Suryanugraha, C. H. (2015). Melagukan Liturgi Menyanyikan Misa. Yogyakarta: Kanisius.

Retrieved from http://repository.unpar.ac.id/bitstream/handle/123456789/967/Suryanurgaha_140604-

p.pdf? sequence $=1 \&$ is Allowed $=\mathrm{y}$

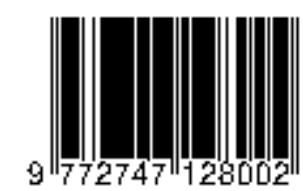

